\title{
Fabrication and Characterization of Antibacterial Polyurethane Acrylate-based Materials
}

\author{
Bihter Zeytuncu ${ }^{a *}$, Mehmet Hakan Morcali \\ ${ }^{a}$ Applied Research Center of Materials Science and Production Technology, \\ Istanbul Technical University - ITU, Maslak, 34469, Istanbul, Turkey \\ ${ }^{b}$ Faculty of Chemical and Metallurgical Engineering, Istanbul Technical University - ITU, \\ Maslak, 34469, Istanbul, Turkey
}

Received: July 1, 2015; Accepted: July 29, 2015

\begin{abstract}
In this paper, the fabrication of the photocured materials which contained silver nanoparticles (Ag-NPs) was studied on the properties of materials such as physical, mechanical and thermal properties, especially antibacterial activity. Therefore, silver nanoparticles were prepared and added into the polyurethane based matrix. Chemical and morphological structures of the photocured materials were characterized by FTIR and SEM analysis. SEM images proved the size of the silver nanoparticles and their dispersion into polymer matrix. Thermal, mechanical and optical properties of photocured materials results showed that the prepared polymer compositions containing Ag-NPs exhibited high modulus and better thermal property. Moreover, the antibacterial properties of the polyurethane based materials and polymer material containing AgNPs were determined and these AgNPs containing photocured materials pointed out good antibacterial activity against Escherichia coli and Staphylococcus aureus.
\end{abstract}

Keywords: polyurethane, photocurable, silver nanoparticles, polyvinylprolidone, antibacterial

\section{Introduction}

Silver is an important element used in various processes. It is used in large quantities for many purposes, particularly in the antibacterial application of coating due to its highest levels of toxicity for microorganisms ${ }^{1-3}$. It has used antibacterial applications of coating materials such as in medicals and healthcare textiles etc. With the arise and increase of microbial organisms resistant to multiple antibiotics, and the continuing point on health-care costs, many researchers have tried to develop new, effective antimicrobial reagents free of resistance ${ }^{3}$. Such problems and needs have led to the resurgence in the use of Ag-based antiseptics that may be linked to broad-spectrum activity and far lower propensity to induce microbial resistance than antibiotics, and there is also important virus activity ${ }^{2,4}$. An adequate amount of free silver ions is required, and while water soluble silver salts can give the necessary high concentrations, this is countered by sequestration by protein and other macromolecules. Loss through insoluble $\mathrm{AgCl}$ and chelating to microbial products is an important problem as well ${ }^{5}$. The antimicrobial properties of Ag hold significant promise; the development of bacterial resistance ${ }^{1,3}$, the mechanism of action ${ }^{6,7}$, toxicology $y^{8,9}$ and clinical utility has been studied greatly for medical applications ${ }^{10,11}$.

Nowadays, polymer modified with silver nanoparticles combinations were studied for a range of non-medical applications ${ }^{12}$, where their electrical conductivity ${ }^{13}$, light scattering and catalytic activity was demonstrated to be valuable ${ }^{14,15}$. The literature contains several works on synthesis of nano silver particle modified coating materials have been investigated ${ }^{13,16-18}$. All synthesized materials result in generally

*e-mail: bihterzeytuncu@gmail.com well but materials usually complex, not straightforward and expensive than our method. Additionally, a heat treatment and evaporation technique, which threatens human life and ecology, spent more energy and time. However, in this work, the polyurethane is modified with nano silver particles by employing UV curing technique in approximately 180 second.

Polyurethane (PU) is an important polymer, used in industry as adhesives, foams, coatings, rubbers and composites ${ }^{15,19}$. Moreover, shape memory and implant materials with their evident biocompatibility have been investigated and their structure and property correlations derived.

Actually, there have been already a lot of methods to prepare silver nanoparticles, including physical vapor deposition, ion implantation, but most of them have difficulties in being scaled up due to the more complex processes or more expensive reaction apparatus ${ }^{1,20}$. Wet chemistry reduction method of $\mathrm{Ag}^{+}$ion is rapidly and effectively using reducing agent such as Sodium borohydride, Citrate, cellulose, D-glucose etc $^{3,5,21}$. However, one of the disadvantages of these methods is that they are not reduced silver from ions to metallic form at all $\mathrm{pH}$ level. Nevertheless, sodium borohydride easily reduces all silver ions to metallic silver at any $\mathrm{pH}$ and after reduction process is not produce any hazardous by product. Typically, the reducing agents provide the reduction reaction such as silver nitrate with a reducing agent like sodium borohydride in the presence of colloidal stabilizer. Sodium borohydride has been used with polyvinyl alcohol (PVA), polyvinylpyrrolidone (PVP), sodium dodecyl sulfate (SDS), bovine serum albumin (BSA), citrate and cellulose as stabilizing agents ${ }^{12,18,22}$. Among all polymer stabilizers of silver nanoparticles, poly(Nvinylpyrrolidone) is considered an excellent dispersant as it exhibits favourable protecting 
properties owing to its unique structure. The PVP protective mechanism of silver nanoparticles formation has been currently described by many researchers ${ }^{16}$. PVP is a homopolymer with a polyvinyl backbone and its repeating units contain a highly polar amide group that confers hydrophilic and polar-attracting properties, and also non-polar methylene groups both in the backbone and in the ring that confer hydrophobic properties. The $\mathrm{N}$ and $\mathrm{O}$ in the polar groups have a strong affinity for silver ions and silver nanoparticles. In general, the PVP protective mechanism is divided into three stages ${ }^{23}$. The first stage involves the formation of coordinative bonding between the stabilizer and silver ions - PVP donates a lone pair of electrons of oxygen and nitrogen to sp orbitals of silver ions. Secondly, the formed complex promotes silver nucleation which leads to the aggregation of silver atoms. Finally, the primary AgNPs coalesce with each other or interact with PVP and form larger aggregates also known as secondary nanoparticles.

The main purpose of this study is to investigate physical, mechanical and thermal properties of PU, loaded with metallic nano sized silver particle along with resultant antimicrobial activity. The products obtained in the study were characterized using FTIR and SEM. The antibacterial activity was studied against Escherichia coli and Staphylococcus aureus.

\section{Material and Methods}

\subsection{Materials}

Silver nitrate $\left(\mathrm{AgNO}_{3}\right)$ and glycerin were purchased from Merck. Sodium borohydride $\left(\mathrm{NaBH}_{4}\right)$ and polyvinylpyrrolidone (PVP) were purchased from Fluka (Germany). Ethoxylated-20- trimethylolpropane triacrylate (TMP20EOTA), 1,6-hexanediol diacrylate (HDDA) and aliphatic urethane acrylate (CN9009) were purchased from Sartomer (USA). Photoinitiator, 2,4,6-Trimethylbenzoyldiphenyl-phosphineoxide (Darocur ${ }^{\circledR}$ TPO), was provided by Ciba Specialty Chemicals. Ultra pure deionized (DI) water was used $\left(0.55 \mu \mathrm{m} / \mathrm{cm}^{2}\right.$, TKA, Germany). Polycarbonate test panels $(70 \mathrm{~mm} \times 100 \mathrm{~mm} \times 1 \mathrm{~mm})$ used as substrates in coating applications were supplied from local suppliers (Turkey).

\subsection{Characterization}

The chemical structures were identified by FTIR spectra recorded on a Perkin-Elmer Spectrum 100 ATR-FTIR spectrophotometer. The transition mode was used and the wavenumber range was set from 4000 to $400 \mathrm{~cm}^{-1}$. SEM imaging of the materials was performed on JEOL JSM 7000F. The specimens were prepared for SEM by freeze-fracturing in liquid nitrogen and applying a platinum coating. Thermogravimetric analyses (TGA) of the photocured materials were performed using a Perkin-Elmer Thermogravimetric analyzer Pyris 1 TGA model. Samples were run from 30 to $750{ }^{\circ} \mathrm{C}$ with heating rate of $10{ }^{\circ} \mathrm{C} / \mathrm{min}$ under nitrogen atmosphere. Mechanical properties were determined by standard tensile stress-strain tests to measure modules $(E)$, ultimate tensile strength $(\delta)$, and elongation at break $(\varepsilon)$. Standard tensile stress-strain experiments were performed at room temperature on a Materials Testing Machine Z010/TN2S apparatus, using a cross-head speed of $5 \mathrm{~mm} / \mathrm{min}$. The contact angles of 3-5 $\mathrm{mL}$ of distilled water, which was applied to the surface by a syringe, were performed by using a Kruss DSA-2 geniometer meaning of sessile drop test method in which drops were created by using a syringe. The image of the liquid drop was captured on a video camera and transferred to a computer screen. Optical properties of photocured materials were examined by using a UV spectrometer (UV2600 Shimadzu).

\subsection{Synthesis of Ag nanoparticles}

Ag nanoparticles (AgNPs) were synthesized similar to the reported procedure in Toker et al. ${ }^{16}$. and An et al. ${ }^{24}$. Aqueous solutions of $\mathrm{AgNO}_{3}(0.1 \mathrm{M}), \mathrm{NaBH}_{4}(0.01 \mathrm{M})$ and PVP $(0.01 \mathrm{M})$ were prepared in deionized water, respectively. Firstly PVP $(0.01 \mathrm{M})$ and $\mathrm{NaBH}_{4}(0.01 \mathrm{M})$ solutions were charged into 2-neck round bottom flask at a volume ratio of $1: 1$ and mixed by agitated with a magnetic stirrer at room temperature. The $\mathrm{AgNO}_{3}(0.1 \mathrm{M})$ solution was then added into the solution drop by drop with the help of a peristaltic pump and stirred continuously (see Figure 1). Until the colorless solution of $\mathrm{NaBH}_{4}-\mathrm{PVP}$ slowly changed from yellow to pale brown, it was continued stirring. The change in color showed the formation of AgNPs. $1.5 \mathrm{~mL}$ Glycerol as a plasticizer per $100 \mathrm{~mL}$ of solution was added and the solution was stirred with a magnetic stirrer for $15 \mathrm{~min}$ at room temperature ${ }^{24}$. The preparation of AgNPs is presented in Figure 1 and the chemical reaction is given by Equation 1.

$\mathrm{AgNO}_{3}+\mathrm{NaBH}_{4} \rightarrow \mathrm{Ag}^{\circ}+1 / 2 \mathrm{H}_{2}+1 / 2 \mathrm{~B}_{2} \mathrm{H}_{6}+\mathrm{NaNO}_{3}$

\subsection{Preparation of photocured materials containing silver nanoparticles}

UV-curable formulation, which is named as control formulation $(\mathrm{CF})$, was prepared by mixing the calculated amounts of aliphatic urethane acrylate resin (UA), HDDA as reactive diluents, TMP20EOTA as a crosslink agent and Darocur $^{\circledR}$ TPO as a photoinitiator. The Ag nanoparticles containing coating formulations were prepared at room temperature for $30 \mathrm{~min}$ mainly from the $\mathrm{CF}$ and six different amounts $[0,1,3,5,7$ and $10 \%(\mathrm{w} / \mathrm{w})]$ of $\mathrm{Ag}$ nanoparticles solution so as to investigate the influence on material properties, especially antibacterial property. The composition of all coating materials is listed in Table 1. Free films were prepared by applying the formulations on to a TeflonTM

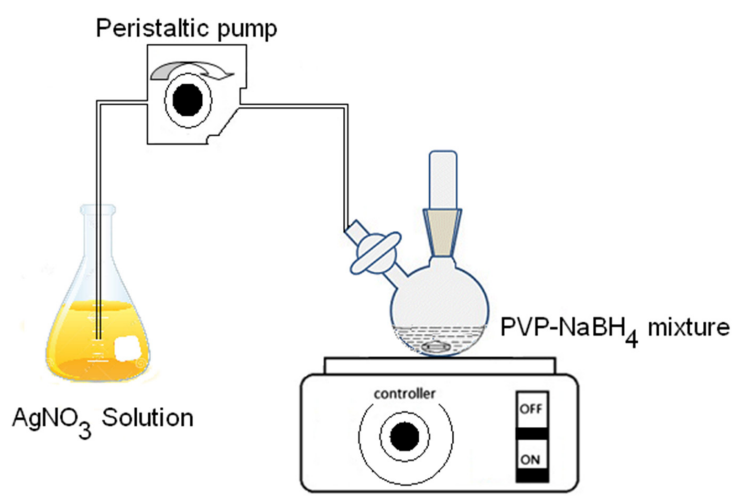

Figure 1. The preparation of AgNPs. 
Table 1. Composition of the formulations.

\begin{tabular}{cccccc}
\hline Samples & $\begin{array}{c}\text { UA } \\
(\mathbf{g})\end{array}$ & $\begin{array}{c}\text { HDDA } \\
(\mathbf{g})\end{array}$ & $\begin{array}{c}\text { TMP20EOTA } \\
(\mathbf{g})\end{array}$ & $\begin{array}{c}\text { Darocur }^{\circledast} \\
(\mathbf{g})\end{array}$ & $\begin{array}{c}\text { TPO } \\
\text { AgNPs sol. } \\
(\mathbf{w t} \%)\end{array}$ \\
\hline CF & 3 & 1.5 & 0.5 & 0.15 & 0 \\
UA-1AgNPs & 3 & 1.5 & 0.5 & 0.15 & 1 \\
UA -2 AgNPs & 3 & 1.5 & 0.5 & 0.15 & 2 \\
UA -3 AgNPs & 3 & 1.5 & 0.5 & 0.15 & 3 \\
UA -5 AgNPs & 3 & 1.5 & 0.5 & 0.15 & 5 \\
UA -7 AgNPs & 3 & 1.5 & 0.5 & 0.15 & 7 \\
UA -10 AgNPs & 3 & 1.5 & 0.5 & 0.15 & 10 \\
\hline
\end{tabular}

coated mold $(10 \mathrm{~mm} \times 50 \mathrm{~mm} \times 1 \mathrm{~mm})$. In order to prevent the inhibiting effect of oxygen, polymer in the mold was covered by transparent Teflon film before irradiation with a high pressure UV-lamp. Irradiation was performed for approximately $180 \mathrm{~s}$. In addition, the polymer formulations were applied on to the corona treated Polycarbonate ${ }^{\circledR}$ panels and cured via UV radiation.

\subsection{Implementation of antibacterial tests}

The antibacterial properties were examined by using the Japanese industrial standard test (JIS Z 2801) against the Gram-negative E. coli and Gram-positive S. aureus ${ }^{25}$. Firstly, stock cultures of the bacteria were grown on plate count agar and then the microorganisms were grown overnight in nutrient rich broth to give a bacterial concentration of approximately $110 \mathrm{CFU} / \mathrm{mL}$ for E. coli and S. aureus. They were diluted with maximum recovery diluent one in a hundred (MRD - $1 \mathrm{w} / \mathrm{v} \%$ peptone, $8.5 \mathrm{w} / \mathrm{v} \% \mathrm{NaCl}$, Oxoid Limited) to give a working culture of approximately 107 and $109 \mathrm{CFU} / \mathrm{mL}$ for E. coli and S. aureus, respectively. The UV-cured test samples being size $5 \times 5 \mathrm{~cm}$ were put into Petri dishes and inoculated with the bacteria cultures and incubated at $37^{\circ} \mathrm{C}$ for $12 \mathrm{~h}$. Then the samples were agitated with MRD $(25 \mathrm{~mL})$ in sterile Stomacher ${ }^{\circledR} 400$ polybags. To dedect the number of colonies, the MRD was diluted tenfold, and the resulting dilutions plated $(100 \mu \mathrm{L})$ onto plate count agar (PCA) for $12 \mathrm{~h}$ incubation at $37^{\circ} \mathrm{C}$.

\section{Results and Discussion}

\subsection{FT-IR Characteristics}

The identification of urethane acrylate oligomer and the preperation of CF and UA-AgNPs were confirmed by ATR-FTIR analysis. As seen in Figure 2a, the absorption bands at 3340, 1726, 1636 and $809 \mathrm{~cm}^{-1}$ attribute to $-\mathrm{NH}$ stretching, $\mathrm{C}=\mathrm{O}$ stretching and $\mathrm{C}=\mathrm{C}$ twisting of acrylate, respectively ${ }^{26}$. After UV-curing, the peaks at 1636 and $809 \mathrm{~cm}^{-1}$ attributed to $\mathrm{C}=\mathrm{C}$ bonds disappeared or decreased (for $\mathrm{CF}$ formulation in Figure $2 \mathrm{~b}$ ). It means that $\mathrm{C}=\mathrm{C}$ bonds in the reactive monomers took part was the cross-linking reaction by photopolymerization ${ }^{27,28}$. Adding AgNPs into the formulations, no difference was observed on the FTIR spectrum apart from a decreasing of peak intensity (Figure 2c).

\subsection{Morphology of the UV-Cured materials}

The morphology of the photocured materials containing AgPNs was investigated by SEM from a fractured surface. The samples were prepared for SEM by freeze-fracturing in liquid nitrogen and applying a gold coating approximately

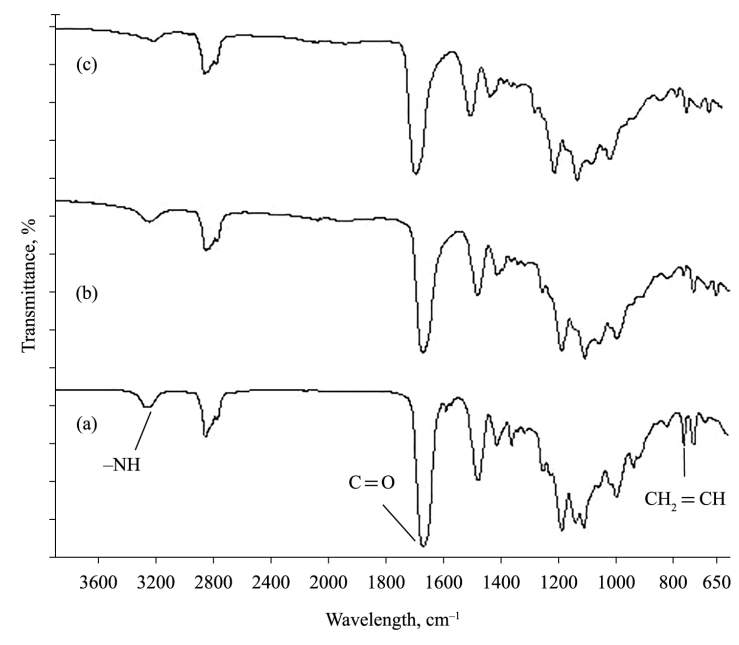

Figure 2. FTIR spectra of (a) urethane acrylate oligomer, (b) CF, and (c) UA -10 AgNPs.

$300 \mathrm{~A}^{\circ}$ in thickness. As seen in Figure 3, SEM image proved the nanostructure and these silver particles dispersed in the photocured polymer materials. The particle size was obtained between 200-300 $\mathrm{nm}$.

\subsection{Thermal properties}

The thermal stability of the photocured materials was investigated by thermogravimetric analysis and the thermograms of these materials in air were shown in Figure 4. The main degradation step of the photocured materials happened at approximately $350-390{ }^{\circ} \mathrm{C}$. While the AgNPs content was increased, the maximum weight loss temperature altered to higher temperatures and char yield also increased ${ }^{12}$. For example, the onset of the thermal degradation and char yield increased about $50{ }^{\circ} \mathrm{C}$ and approximately $8.5 \%$ for the containing with $10 \mathrm{wt} \%$ of Ag-NPs. The final weight loss attributed that the photocured polymer materials completely degraded was observed around at $460{ }^{\circ} \mathrm{C}$. The char yield at $750{ }^{\circ} \mathrm{C}$ was collected and the obtained results were presented in Table 2. Therefore, the results indicate that the photocured materials are thermally stable at temperatures up to about $450{ }^{\circ} \mathrm{C}$.

\subsection{Mechanical properties}

The mechanical properties of photocured materials were evaluated and the stress-strain data of the materials as a function of AgNPs content were given in Table 3. According to the results, the modulus of the photocured 
materials increased with increasing amount of AgNPs. It can be noted that the increasing can be ascribed to having more crosslinking density of UA-AgNPs materials than the based materials. On the contrary, tensile strength of the UA-AgNPs materials first increased with the addition of AgNPs then decreased constantly with increasing amount of AgNPs.

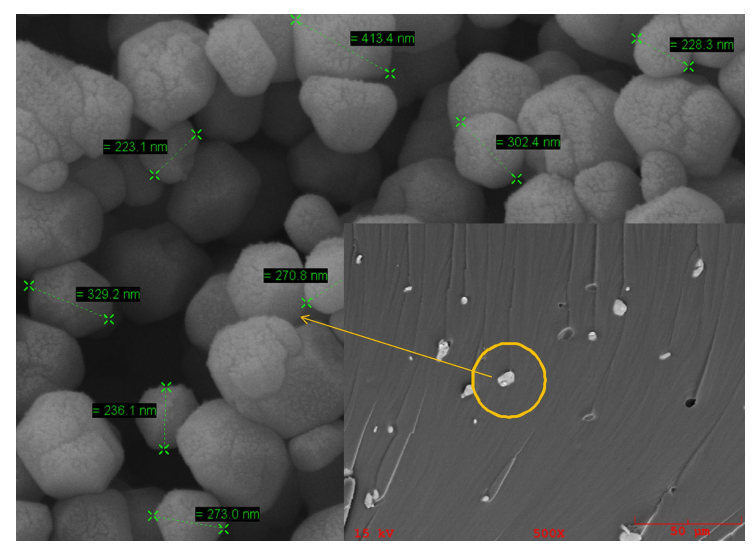

Figure 3. SEM micrographs of the photocured materials containing AgPNs.

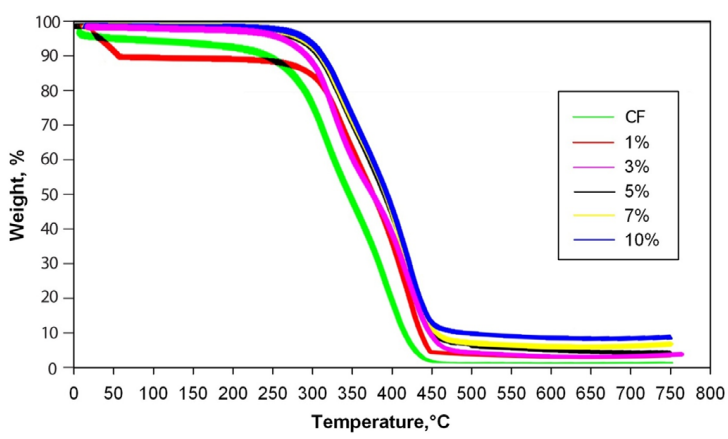

Figure 4. TGA spectra of photocured materials.

Table 2. Thermal properties of photocured materials.

\begin{tabular}{cccc}
\hline Samples & $\begin{array}{c}\text { Max weight } \\
\text { loss, }{ }^{\circ} \mathbf{C}\end{array}$ & $\begin{array}{c}\text { Final weight } \\
\text { loss, }{ }^{\circ} \mathbf{C}\end{array}$ & $\begin{array}{c}\text { Char yield, } \\
\text { \% }\end{array}$ \\
\hline CF & 348 & 450 & 1.03 \\
UA-1AgNPs & 374 & 447 & 4.98 \\
UA -3 AgNPs & 376 & 471 & 5.12 \\
UA -5 AgNPs & 384 & 466 & 6.17 \\
UA -7 AgNPs & 387 & 468 & 7.48 \\
UA -10 AgNPs & 398 & 459 & 9.52 \\
\hline
\end{tabular}

Furthermore, the elongation at break values decreased when the concentration of nanoparticles was increased. The movement of the polymer chains is restricted owing to the presence of the AgNPs and thus the elongation at break values are reducing. As a consequence, the presence of AgNPs caused these photocured materials to be stronger but rather brittle.

\subsection{Optical properties}

Optical property of photocured materials was tested by measuring UV-transmittance value and the transmission spectra of films in the range between 300 and $800 \mathrm{~nm}$ was shown in Figure 5. Furthermore, the values at $550 \mathrm{~nm}$ were given in Table 3. As seen in Figure 5, the optical transmittance of photocured materials decreased with increasing amount of AgNPs due to the fact that the silver particles dispersed in the polymer matrix. Hence, lower transparency was observed because of the scattering of light by AgNPs in the UV-cured materials while AgNPs concentration increased.

\subsection{Surface wettability properties}

The contact angle measurements, which were taken from the left and right sides of the droplet, for surface wettability of the photocured materials were reported in Table 3 . The contact angles of distilled water were measured immediately after the drop was settled on the UV-cured film surface. As seen from Table 3, the water contact angle of CF was found as $77^{\circ}$. Firstly, the addition of AgNPs solution into the formulation, the surface of the UA based films became roughened and the contact angle values increased. Then the increasing

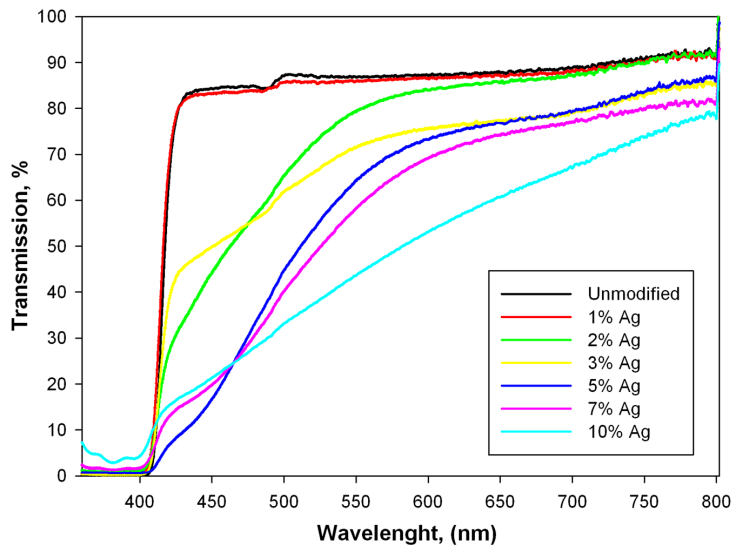

Figure 5. Transmission spectra of photocured materials.

Table 3. The physical and mechanical properties of UV-cured materials.

\begin{tabular}{cccccc}
\hline Sample & $\begin{array}{c}\text { Young's modulus } \\
\left(\mathbf{N} / \mathbf{m m}^{\mathbf{2}}\right)\end{array}$ & $\begin{array}{c}\text { Tensile Strength } \\
\mathbf{( N )}\end{array}$ & $\begin{array}{c}\text { Elongation at } \\
\text { break } \mathbf{( \% )}\end{array}$ & $\begin{array}{c}\text { Contact Angle } \\
(\mathbf{(})\end{array}$ & $\begin{array}{c}\text { UV Transmittance } \\
(\mathbf{\%}) \mathbf{a t} \mathbf{5 5 0} \mathbf{~ n m}\end{array}$ \\
\hline CF & 4.57 & 78 & 33 & 77.2 & 86.78 \\
UA-1AgNPs & 84.4 & 164 & 36 & 79.9 & 85.93 \\
UA-2 AgNPs & 134 & 192 & 30 & 76.7 & 79.26 \\
UA-3 AgNPs & 178 & 183 & 29 & 70.5 & 71.48 \\
UA-5 AgNPs & 204 & 182 & 25 & 68.5 & 64.29 \\
UA-7 AgNPs & 224 & 168 & 16 & 67.7 & 58.20 \\
UA-10AgNPs & 273 & 157 & 14 & 64.9 & 43.55 \\
\hline
\end{tabular}




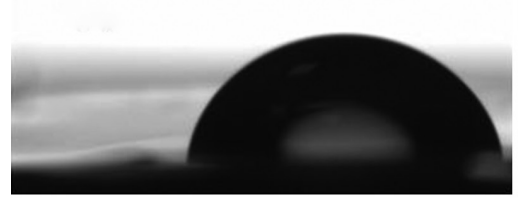

(a)

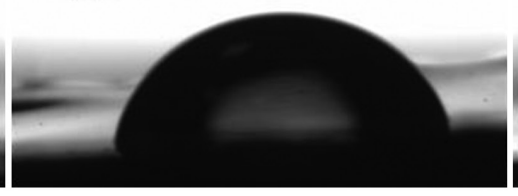

(b)

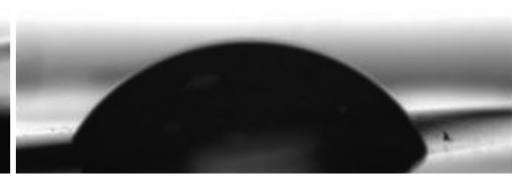

(c)

Figure 6. Contact angle images of water drop on (a) CF, (b) UA-1AgNPs, and (c) UA-10AgNPs.

Table 4. Antibacterial activities of UV-cured materials.

\begin{tabular}{ccccccc}
\hline \multicolumn{7}{c}{ Bacterial load $(\mathbf{C F U} / \mathbf{m L})$} \\
\hline Sample & E. coli & & & S. aureus \\
\hline Bacterial control & $5.40 \mathrm{E}+5$ & $24 \mathbf{h}$ & LOG reduction & Start & $\mathbf{2 4 h}$ & LOG reduction \\
PC & $6.03 \mathrm{E}+5$ & $4.17 \mathrm{E}+5$ & -0.2 & $2.60 \mathrm{E}+6$ & $3.00 \mathrm{E}+4$ & \\
CF & $5.74 \mathrm{E}+5$ & $3.94 \mathrm{E}+4$ & 0.5 & $2.80 \mathrm{E}+6$ & $2.10 \mathrm{E}+4$ & 0.3 \\
UA-10AgNPs & $6.58 \mathrm{E}+5$ & $<30$ & $>5.2$ & $2.10 \mathrm{E}+6$ & $7.62 \mathrm{E}+3$ & 0.9 \\
\hline
\end{tabular}

amount of AgNPs in the polymer matrix, the water contact angle values decreased because of hydrophilic nature of the AgNPs solution. There are 3 different images in Figure 6 that were taken from the Kruss software. Generally gloss values of polymer/inorganic composites decrease due to the rough surface of these materials.

\subsection{Antibacterial properties}

The antibacterial activity of photocured materials and containing AgNPs materials was tested by using Gram-negative E. coli and Gram-positive S. aureus and waited for $24 \mathrm{~h}$. The obtained results were given in Table 4 . During $12 \mathrm{~h}$ incubation of the inoculated materials added AgNPs resulted in almost 99\% $(<30 \mathrm{CFU} / \mathrm{mL})^{25}$ reduction in bacterial colonies compared to control formulation (CF) which based on polyurethane acrylate. Accordance with the data, it is obvious that the photocured materials containing AgNPs have bacteria resistance, especially against E. coli and S. aureus. While antibacterial activity results were compared with other literatures, it was observed that the similar results were obtained effectively $y^{3,6,15,16,21}$.

\section{References}

1. Prabhu S, Poulose EK and Poulose EK. Silver nanoparticles: mechanism of antimicrobial action, synthesis, medical applications, and toxicity effects. International Nano Letters. 2012; 2(1):1-10. http://dx.doi.org/10.1186/2228-5326-2-32.

2. Zhao G and Stevens SE Jr. Multiple parameters for the comprehensive evaluation of the susceptibility of Escherichia coli to the silver ion. Biometals. 1998; 11(1):27-32. http:// dx.doi.org/10.1023/A:1009253223055. PMid:9450315.

3. Kim JS, Kuk E, Yu KN, Kim JH, Park SJ, Lee HJ, et al. Antimicrobial effects of silver nanoparticles. Nanomedicine; Nanotechnology, Biology, and Medicine. 2007; 3(1):95-101. http://dx.doi.org/10.1016/j.nano.2006.12.001. PMid:17379174.

4. Slawson R, Trevors JT and Lee H. Silver accumulation and resistance in Pseudomonas stutzeri. Archives of Microbiology. 1992; 158(6):398-404. http://dx.doi.org/10.1007/BF00276299.

\section{Conclusion}

In this study, it was aimed to prepare colloidal silver nanoparticles stabilized with polyurethane acrylate-based materials in a simple oxidation-reduction reaction in sodium borohydride and silver nitrate in aqueous solution. The properties of materials were studied such as physical, mechanical and thermal properties as well as antibacterial activity. Due to strong antibacterial activity, $1-10 \mathrm{wt} \%$ adapted silver nanoparticles containing UV curable materials were prepared. Based on the results presented in the study above can be concluded that the UV Transmittance (\%) test at $550 \mathrm{~nm}$ showed that the transmittance was decreased with increasing the amount of AgNPs adapted PU materials. In addition, the evident from SEM results, the adding AgNPs was good mixed and well dispersed in the polymer matrix. The silver composite materials have improved mechanical properties and greater thermal stability, but the feasibility of silver loading for such an application would need further evaluation. The nano-silver containing materials exhibited good antibacterial activity against E. coli and S. aureus. It is understood that the existed of the nano silver particle advanced the antibacterial activity of the urethane acrylate based materials.

5. Paul D, Paul S, Roohpour N, Wilks M and Vadgama P. Antimicrobial, mechanical and thermal studies of silver particleloaded polyurethane. Journal of Functional Biomaterials. 2013; 4(4):358-375. http://dx.doi.org/10.3390/jfb4040358. PMid:24956194.

6. Russell AD, Hugo WB, Pharm FR and Hugo WB. Antimicrobial activity and action of silver. Progress in Medicinal Chemistry. 1994; 31:351-370. http://dx.doi.org/10.1016/S0079-6468(08)70024-9. PMid:8029478.

7. Lansdown AB. Silver. I: Its antibacterial properties and mechanism of action. Journal of Wound Care. 2002; 11(4):125-130. http:// dx.doi.org/10.12968/jowc.2002.11.4.26389. PMid:11998592.

8. Hussain SM, Hess KL, Gearhart JM, Geiss KT and Schlager JJ. In vitro toxicity of nanoparticles in BRL $3 \mathrm{~A}$ rat liver cells. Toxicology In Vitro. 2005; 19(7):975-983. http://dx.doi. org/10.1016/j.tiv.2005.06.034. PMid:16125895. 
9. Lansdown AB. Silver. 2: Toxicity in mammals and how its products aid wound repair. Journal of Wound Care. 2002; 11(5):173-177. http://dx.doi.org/10.12968/jowc.2002.11.5.26398. PMid:12055941.

10. Kirsner R, Orsted H and Wright B. Matrix metalloproteinases in normal and impaired wound healing: a potential role of nanocrystalline silver. Wounds: a Compendium of Clinical Research and Practice. 2001; 13:5-10.

11. White RJ. An historical overview of the use of silver in wound management. British Journal of Community Nursing. 2001; 6(Sup1):3-8. http://dx.doi.org/10.12968/bjcn.2001.6.Sup1.12619.

12. Mbhele ZH, Salemane MG, Van Sittert CGCE, Nedeljkovic JM, Djokovic V and Luyt AS. Fabrication and characterization of silver-polyvinyl alcohol nanocomposites. Chemistry of Materials. 2003; 15(26):5019-5024. http://dx.doi.org/10.1021/ cm034505a.

13. Lu HW, Liu SH, Wang XL, Qian XF, Yin J and Zhu ZK. Silver nanocrystals by hyperbranched polyurethane-assisted photochemical reduction of Ag+. Materials Chemistry and Physics. 2003; 81(1):104-107. http://dx.doi.org/10.1016/ S0254-0584(03)00147-0.

14. Razi MK, Azadi S, Mamoory RS and Mohammadi M. Preparation of nano silver powder from acid leaching tail in gold room. International Journal of Nano Dimension. 2010; 1(2):133-142.

15. Liu HL, Dai SA, Fu KY and Hsu SH. Antibacterial properties of silver nanoparticles in three different sizes and their nanocomposites with a new waterborne polyurethane. International Journal of Nanomedicine. 2010; 5(1):1017-1028. PMid:21187943.

16. Toker RD, Kayaman-Apohan N and Kahraman MV. UV-curable nano-silver containing polyurethane based organic-inorganic hybrid coatings. Progress in Organic Coatings. 2013; 76(9):12431250. http://dx.doi.org/10.1016/j.porgcoat.2013.03.023.

17. Akamatsu K, Takei S, Mizuhata M, Kajinami A, Deki S, Takeoka $\mathrm{S}$, et al. Preparation and characterization of polymer thin films containing silver and silver sulfide nanoparticles. Thin Solid Films. 2000; 359(1):55-60. http://dx.doi.org/10.1016/S00406090(99)00684-7.

18. Lee S, Song K and Lee B. Antibacterial activity of silver nanoparticles prepared by a chemical reduction method. Korean Journal of Chemical Engineering. 2010; 27(2):688-692. http:// dx.doi.org/10.1007/s11814-010-0067-0.

19. Ti Y, Wu JR and Chen DJ. The characterization of a new antibacterial polyurethane. Advanced Materials Research.
2013; 750-752:1609-1612. http://dx.doi.org/10.4028/www. scientific.net/AMR.750-752.1609.

20. Abuskhuna S, Briody J, McCann M, Devereux M, Kavanagh $\mathrm{K}$, Fontecha JB, et al. Synthesis, structure and anti-fungal activity of dimeric $\mathrm{Ag}(\mathrm{I})$ complexes containing bis-imidazole ligands. Polyhedron. 2004; 23(7):1249-1255. http://dx.doi. org/10.1016/j.poly.2004.02.006.

21. Lin S, Chen L, Huang L, Cao S, Luo X and Liu K. Novel antimicrobial chitosan-cellulose composite films bioconjugated with silver nanoparticles. Industrial Crops and Products. 2015; 70:395-403. http://dx.doi.org/10.1016/j.indcrop.2015.03.040.

22. Sheehy K, Casey A, Murphy A and Chambers G. Antimicrobial properties of nano-silver: a cautionary approach to ionic interference. Journal of Colloid and Interface Science. 2015; 443:56-64. http://dx.doi.org/10.1016/j.jcis.2014.11.074. PMid:25531416.

23. Dagmara M, Agnieszka S-K, Zbigniew W and Zygmunt K. Silver nanoparticles synthesis with different concentrations of polyvinylpyrrolidone. Digest Journal of Nanomaterials and Biostructures. 2012; 7(4):1527-1534.

24. An J, Zhang M, Wang S and Tang J. Physical, chemical and microbiological changes in stored green asparagus spears as affected by coating of silver nanoparticles-PVP. LWT-Food Science and Technology. 2008; 41(6):1100-1107. http://dx.doi. org/10.1016/j.lwt.2007.06.019.

25. Michels HT, Noyce JO and Keevil CW. Effects of temperature and humidity on the efficacy of methicillin-resistant Staphylococcus aureus challenged antimicrobial materials containing silver and copper. Letters in Applied Microbiology. 2009; 49(2):191195. http://dx.doi.org/10.1111/j.1472-765X.2009.02637.x. PMid:19413757.

26. Bayramoğlu G, Kahraman MV, Kayaman-Apohan N and Güngör A. Synthesis and characterization of UV-curable dual hybrid oligomers based on epoxy acrylate containing pendant alkoxysilane groups. Progress in Organic Coatings. 2006; 57(1):50-55. http://dx.doi.org/10.1016/j.porgcoat.2006.06.002.

27. Park Y-J, Lim D-H, Kim H-J, Park D-S and Sung I-K. UV- and thermal-curing behaviors of dual-curable adhesives based on epoxy acrylate oligomers. International Journal of Adhesion and Adhesives. 2009; 29(7):710-717. http://dx.doi.org/10.1016/j. ijadhadh.2009.02.001.

28. Kunwong D, Sumanochitraporn N and Kaewpirom S. Curing behavior of a UV-curable coating based on urethane acrylate oligomer: the influence of reactive monomers. Sonklanakarin Journal of Science and Technology. 2011; 33(2):201. 